Supporting Information

\title{
Tumor-penetrating hierarchically-structured nano-marker for imaging-guided urinary monitoring of cancer
}

Xiao-Jing Zhang ${ }^{1}$, Lin $\mathrm{Yu} \mathrm{Hu}^{1}$, \# Yue Hu${ }^{1}$, Xiao-Tong Yang ${ }^{1}$, Ying-Ying Tang ${ }^{1}$, Yu Ying Tang ${ }^{1}$, Su Li ${ }^{1}$, Dong Zhu*1

${ }^{1}$ School of Pharmacy, Nanjing University of Chinese Medicine, Nanjing, Jiangsu, 210023, P. R. China.

\# These authors contributed equally to this work.

*Corresponding author. E-mail: dongzhu@njucm.edu.cn;

Fax: +86 2585811839; Tel: +862585811839 


\section{Cell flow cytometry assay.}

The cells were inplanted in a 6-well plate and cultured for one night. After washing with PBS, the cells were incubated with different concentrations of the nano-marker dispersed in complete medium. And then cells were collected with cell scraper at $4{ }^{\circ} \mathrm{C}$ analyzed by flow cytometry.

\section{ELISA assay for breast cancer biomarkers (CA 15-3) in blood}

The blood sample was obtained by capillary blood collection at the corresponding measurement using the nano-marker. Approximately $100 \mu \mathrm{L}$ of blood was collected in $1.5 \mathrm{ml}$ Eppendorf tube coated with heparin and centrifuged at $9000 \mathrm{rpm}$ for $10 \mathrm{~min}$. Serum (the supernatants) was collected and stored at $-20{ }^{\circ} \mathrm{C}$ for CA15-3 quantification. Secreted and cytoplasmic levels of CA-153 were measured using ELISA kit according to the manufacturer's protocol.

\section{Nano-marker distribution in organs.}

To know the nano-marker distribution in organs, mice were killed after $3 \mathrm{~h}$ of caudal vein execution, and all organs (heart, liver, spleen, lung, kidney, tumor) were retrieved, collected and stored in $4 \%$ paraformaldehyde at room temperature. Frozen sections of the organs was performed with a series of operations. Immunofluorescence sections was imaged. And then fluorescence of the nano-marker itself (emission $680 \mathrm{~nm}$ ) was quantified by the ImageJ software package.

\section{Toxicity and clearance of the nano-marker.}

All studies were administrated using six- and eight-week-old female immunocompetent $\mathrm{BALB} / \mathrm{c}$ mice. After injection of the nano-marker, $20 \mu \mathrm{l}$ of blood were respectively collected at different time for fluorescent detection. After centrifugation of $3000 \mathrm{rpm}$ for $10 \mathrm{~min}$ at $4{ }^{\circ} \mathrm{C}$, serum was collected and diluted 10-fold to measure the fluorescent intensity of $680 \mathrm{~nm}$. For tissue histopathological examination, the mice were sacrificed and their organs were excised, fixed in $4 \%$ formalin. After being embedded in paraffin and sectioned, Organs imaging was completed for Haematoxylin and eosin(HE)-stained sections. 


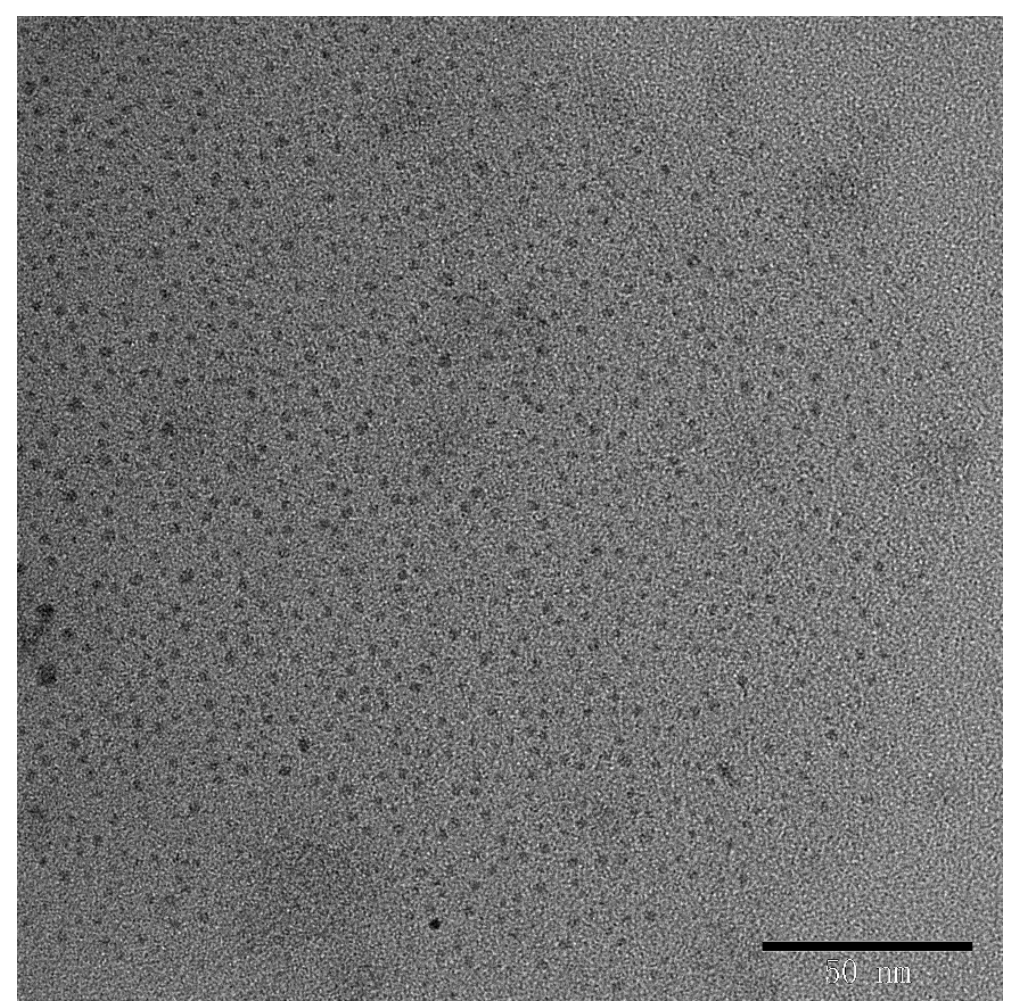

Figure S1. TEM image of thiol-functionalized silica nanoparticles as the innermost core.

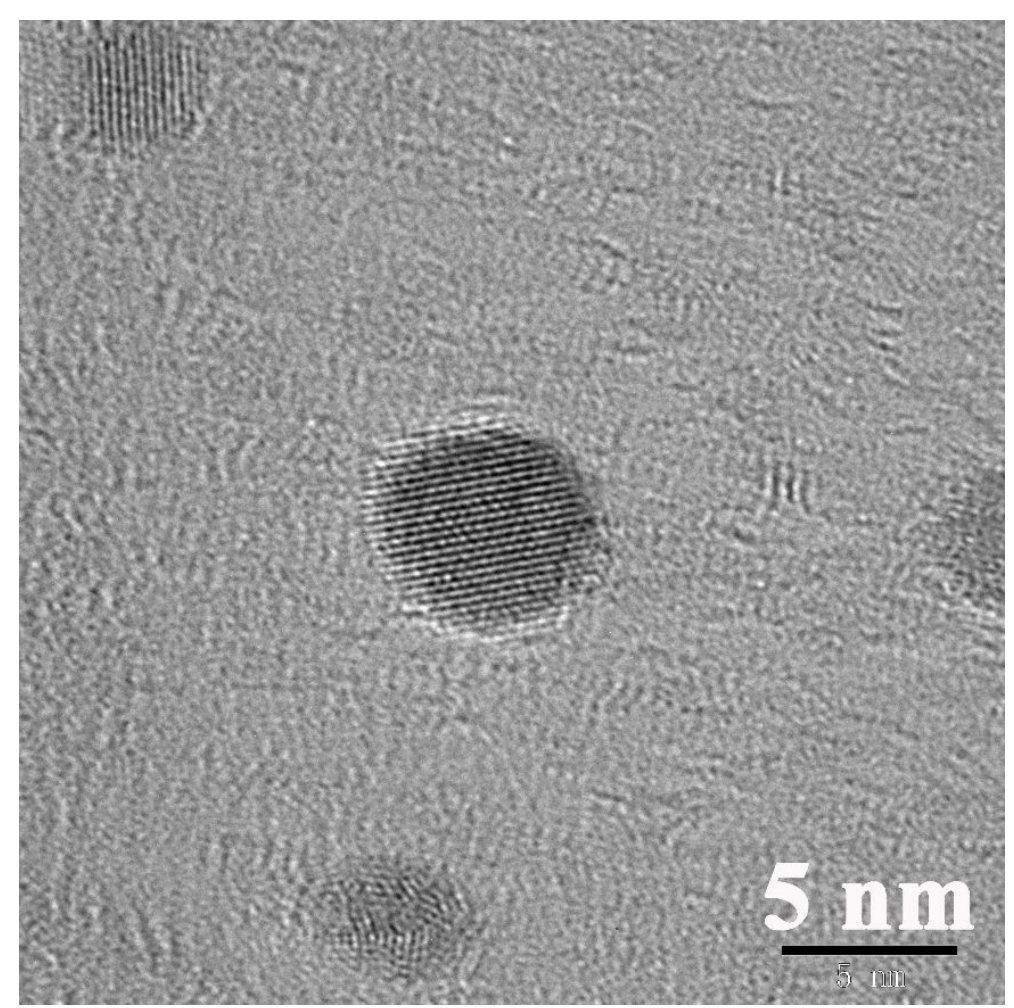

Figure S2. TEM images of $\mathrm{SiO}_{2} @ \mathrm{CdTe}$ nanoparticles. 


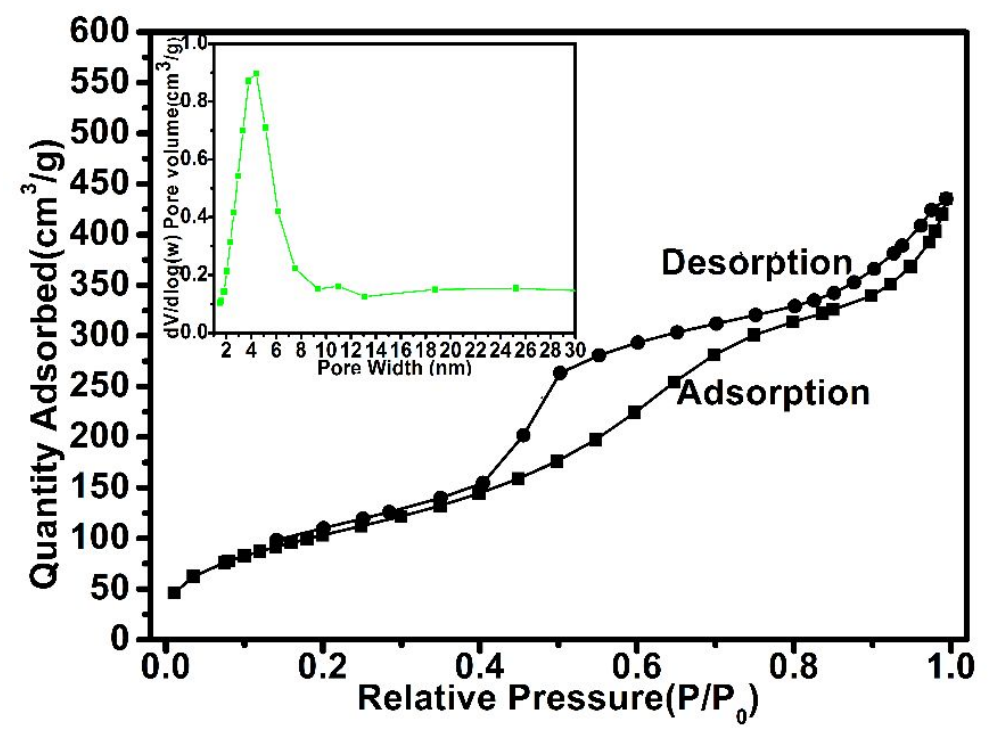

Figure S3. $\mathrm{N}_{2}$ adsorption-desorption isotherms and pore-size distribution of the DMS.
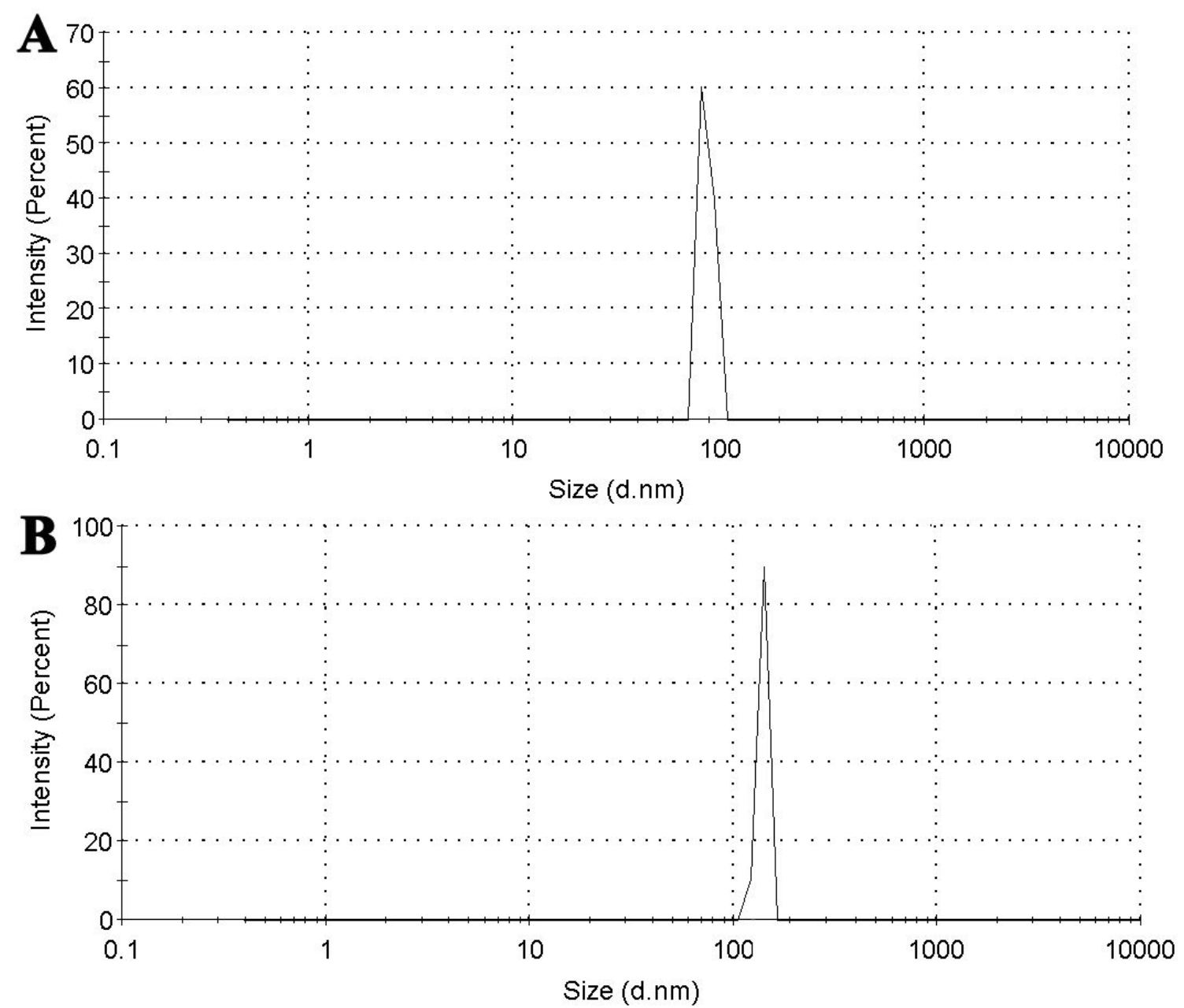

Figure S4. Effect of linker PEG on hydrodynamic size of the DMS. DLS size profiles of the DMS without PEG in PBS (A) and the DMS with PEG (B).

Compared to the FI-IR spectrum of DMS (showed in Figure S5A), two absorption peak at 1636 and $935 \mathrm{~cm}^{-1}$ appeared respectively due to the stretching vibration of $\mathrm{C}=\mathrm{C}$ bond and bending vibration of $\mathrm{C}-\mathrm{H}$ bond of PEG derivatives on the PEG-DMS. The new peaks at 1104 and $1041 \mathrm{~cm}^{-1}$ were due to the stretching vibration of $\mathrm{C}-\mathrm{O}$ and $\mathrm{C}-\mathrm{N}$ bond of substrate peptide, 
suggesting the successful combination of peptide to our nano-marker. Moreover, after addition of pure substrate peptide to our nano-marker, a new absorption around $488 \mathrm{~nm}$ in the UV-vis spectrum appeared (Figure S5B), further indicating the combination of peptide to our nanomarker.
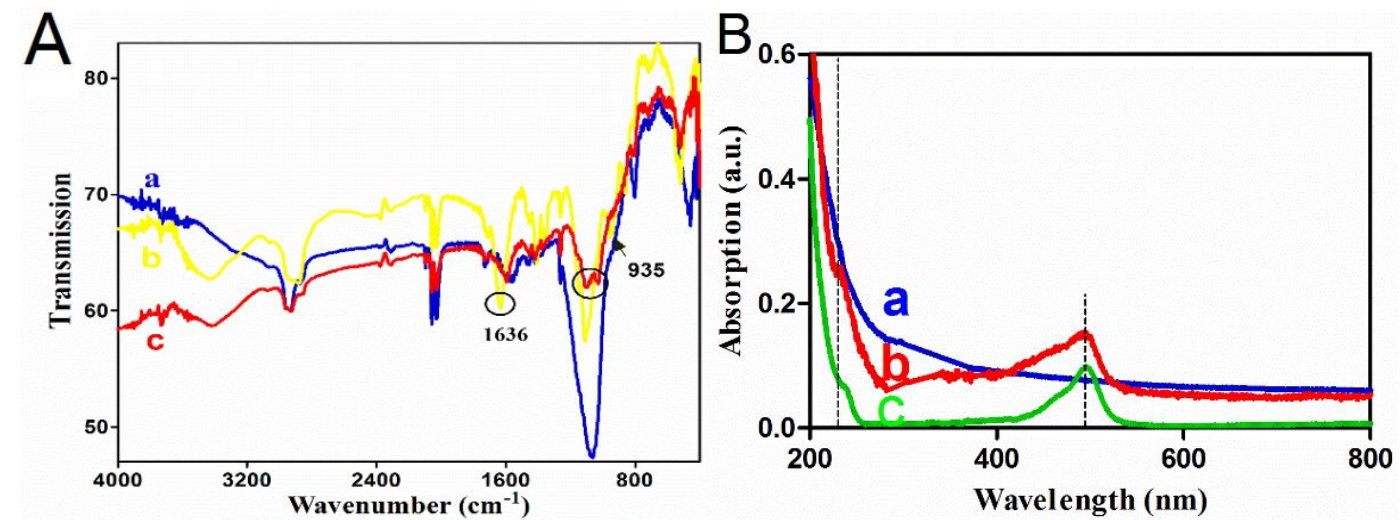

Figure S5. (A).FI-IR spectrum of (a) APS-DMS, (b) PEG linker-DMS, (c) a MMP-2 specific substrate peptide decorated DMS (B) the corresponding UV-vis spectrum of (a) PEG linkerDMS, (b) a MMP-2 specific substrate peptide decorated DMS and (c) DMS decorated with a cyclic tumour-penetrating peptide (iRGD (C-PEG2-CRGDKGPDC)).

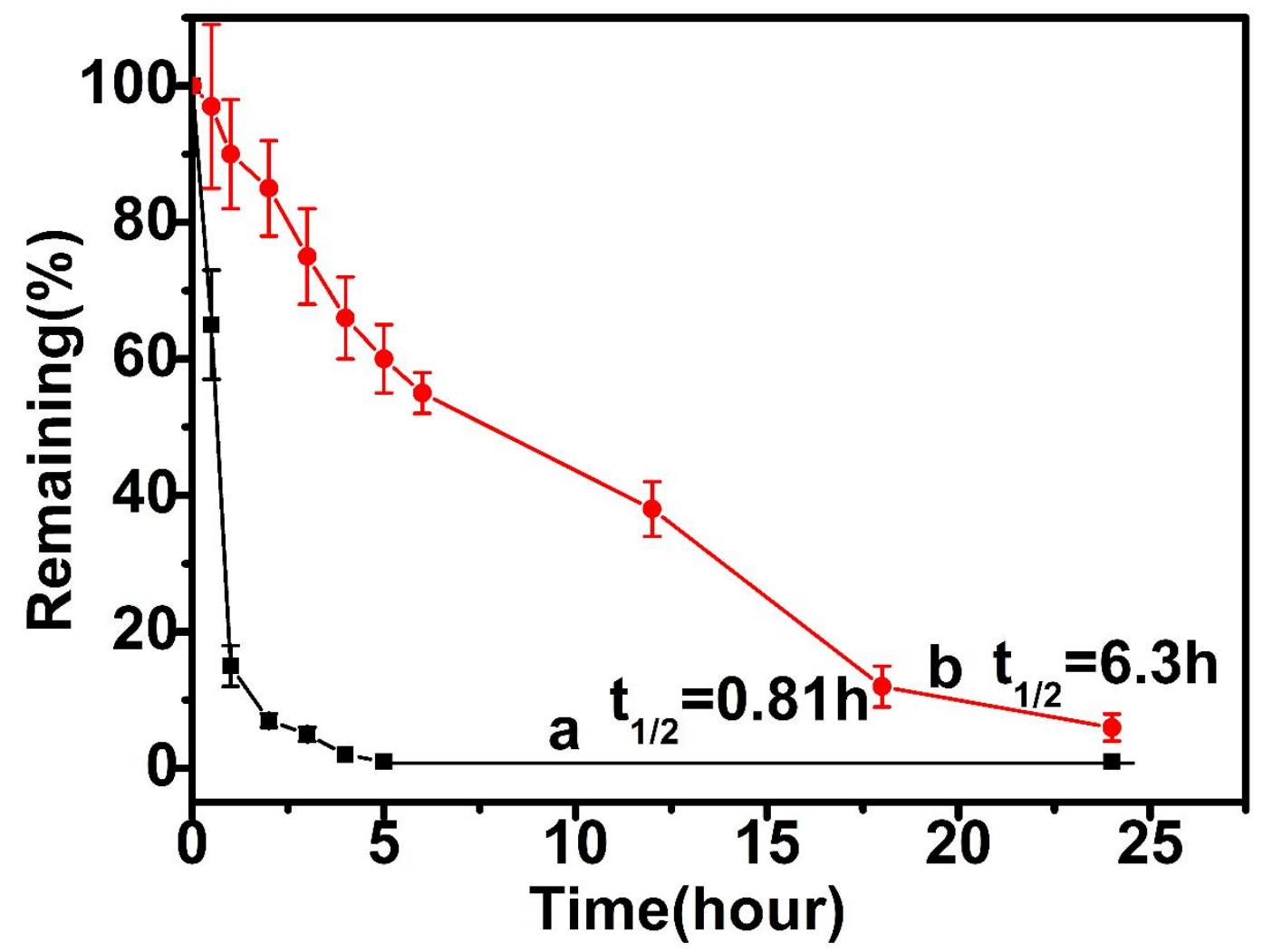

Figure S6. Half-life measurements of pure DMS (a) and nano-marker decorated with a MMP2 specific substrate peptide by a PEG linker (MAL-PEG-SVA). 


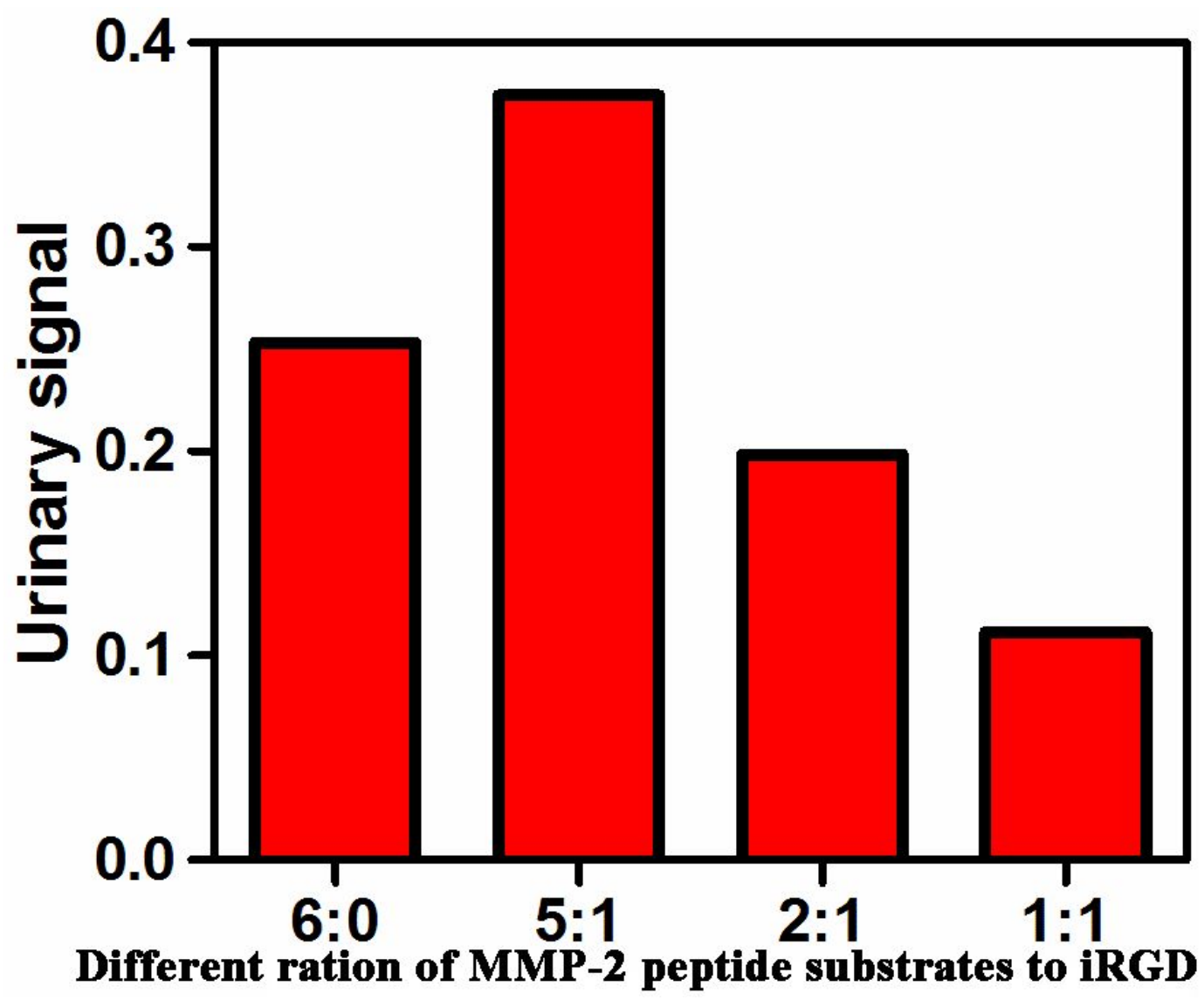

Figure S7. Urinary measurement of different mole ration of MMP-2 peptide substrates to iRGD.

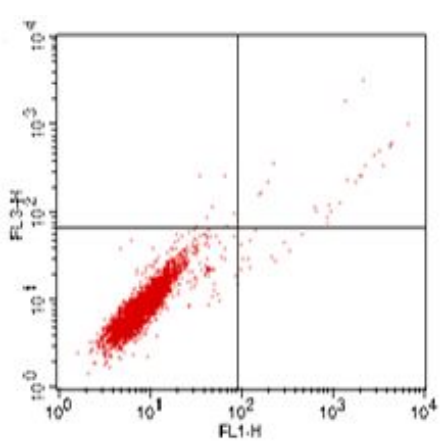

Control

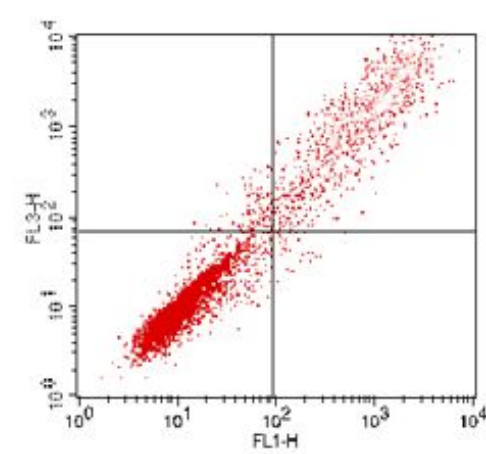

DMS without iRGD

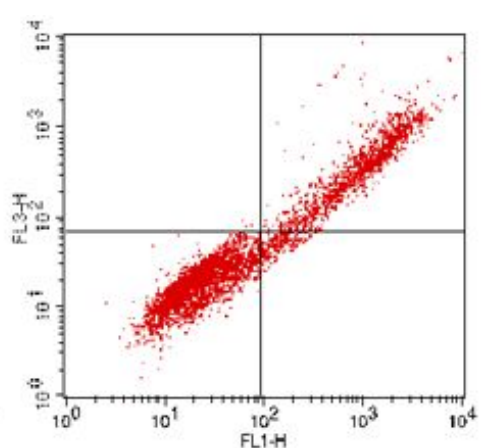

DMS functionalized withiRGD

Figure S8. Flow cytometry measurement of 4T1 incubated with DMS without iRGD and DMS functionalized with iRGD. Control: 4T1 cell without any material.

$\mathbf{A}$

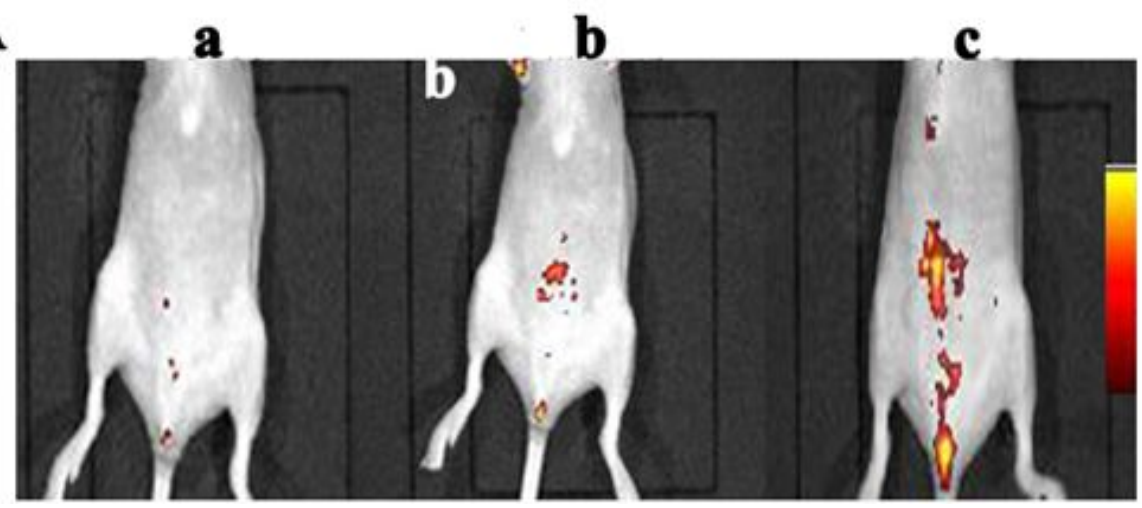



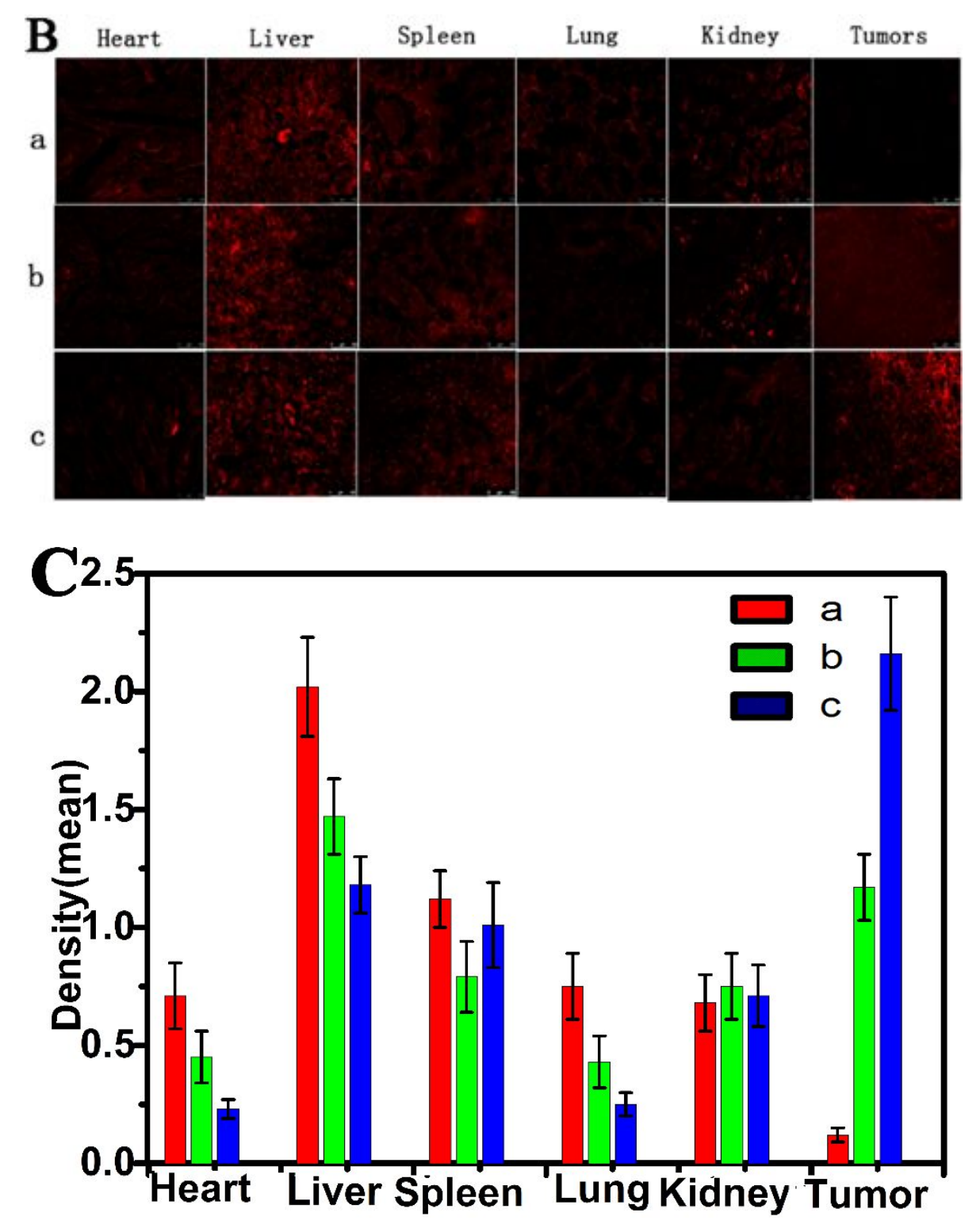

Figure S9. (A). Accumulation of the nano-marker with iRGD in healthy mice (control, a) or tumor mice (c), and of the nano-marker without iRGD in tumor mice (b). (B) Fluorescent tissue slices from healthy mice (control, a) or tumor mice administered with the nano-marker without iRGD (b), and the nano-marker functionalized with iRGD (c). (C) the corresponding quantification of the fluorescent signal from DMS in tumors and organs. The error bars were calculated from three mice. 


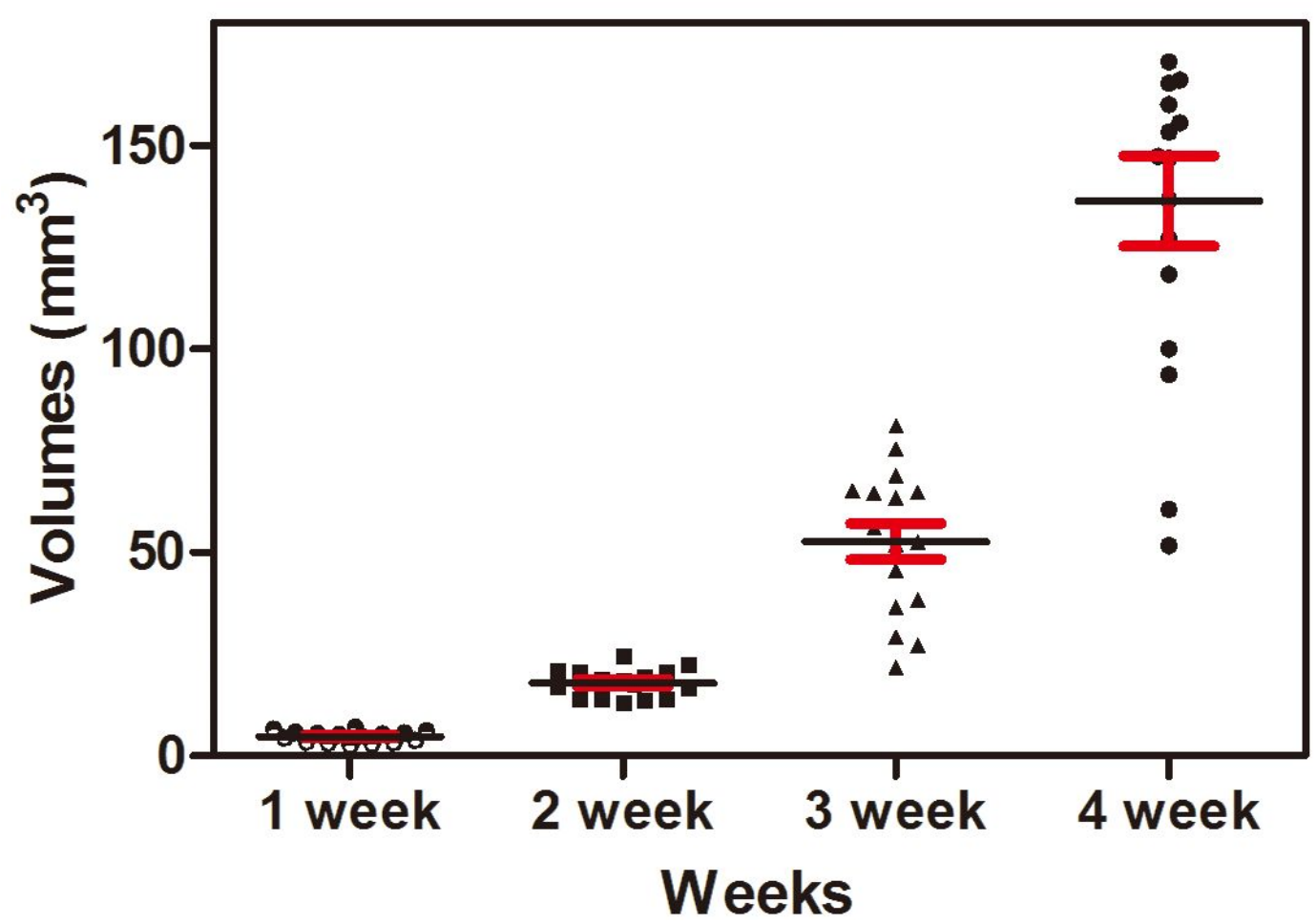

Figure S10. Volume of mice tumor with weekly changing.
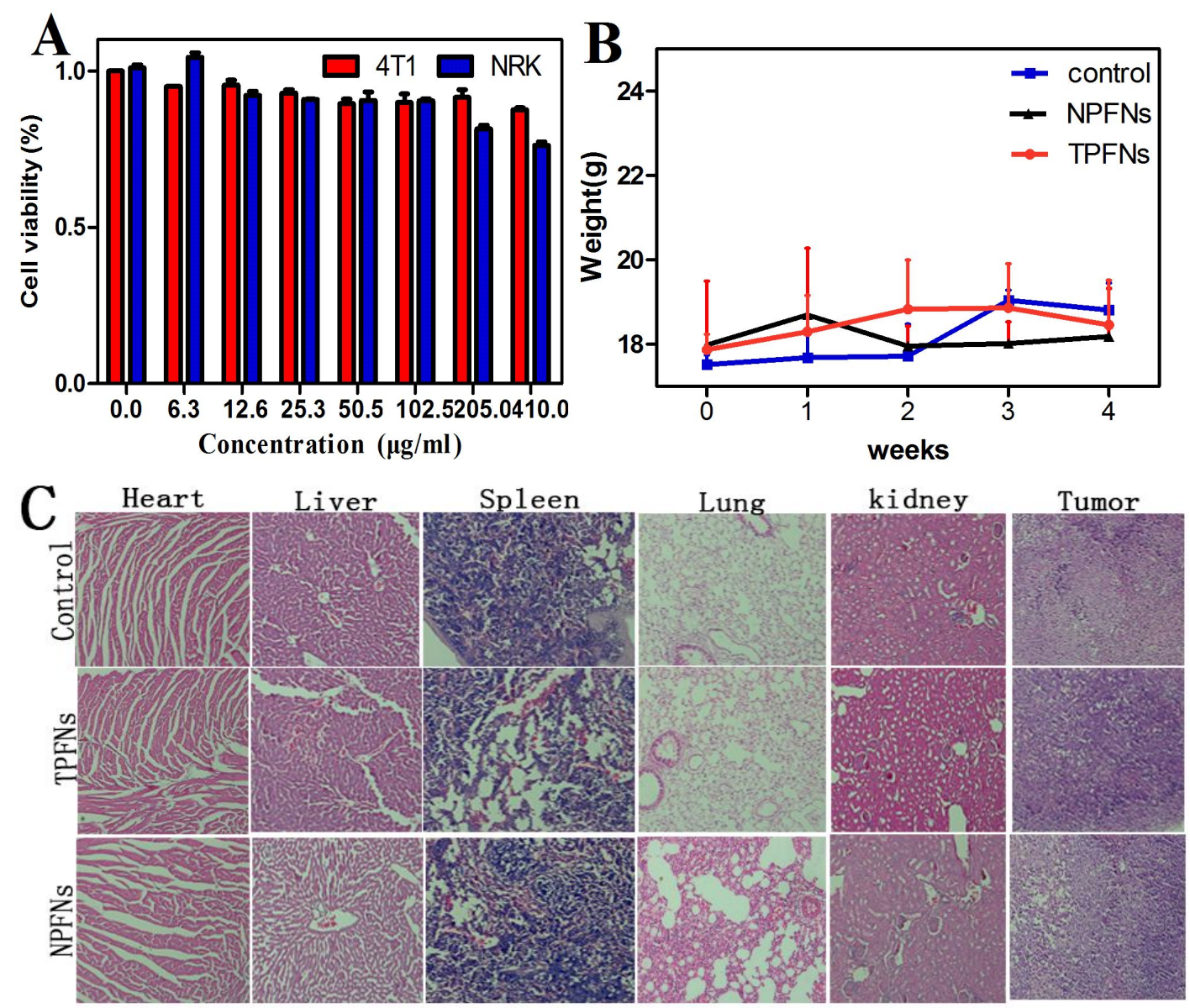

Figure S11. (A) Cell viability of the nano-marker incubated with 4T1 and NRK cells. (B) The change of the body weight over the regimen. (C) Histological examination of heart, liver, spleen, lung, and kidney. 